\title{
Radioisotope determination of regional colonic transit in severe constipation: comparison with radio opaque markers
}

\author{
J R M van der Sijp, M A Kamm, J M D Nightingale, K E Britton, S J Mather, G P Morris, \\ L M A Akkermans, J E Lennard-Jones
}

\begin{abstract}
Radio-opaque markers have a well established role in distinguishing between patients with normal and those with slow intestinal transit, but in the latter group their accuracy in defining the region of delay has not been established. To study regional colonic transit accurately the transit of a radioisotope labelled meal was determined and findings were compared with those of simultaneously ingested radio-opaque markers. Twelve healthy controls (mean age 33 years) and 12 severely constipated women (mean age 36 years, bowel frequency $<$ once per week) were studied On day 1 , a meal containing $10 \mathrm{MBq}{ }^{11}$ In bound to $0.7 \mathrm{~mm}$ resin microspheres was ingested. Subjects also ingested a set of radiologically distinguishable markers on three successive days. Abdominal scans were obtained three times daily for 7 days. Abdominal radiographs were obtained after 72 or 96 hours and again at 144 or 168 hours. Eight 'regions of interest' were created - one for the small bowel, six for the colon, and one for excreted stool. The constipated patients all showed colonic transit outside the normal range, with a variable site of delay demonstrated by time activity curves for each region. To provide a different measure of the effectiveness of colonic transport, the movement of the 'centre of mass' for the radioisotope and for the markers was then determined. The radioisotope and radiopaque marker methods gave similar results. At all times between 24 and 144 hours there was no significant difference for the position of the centre of mass between the radio-opaque and marker methods. At all times, however, the mean difference between the markers and the radioisotopes was positive, indicating that the centre of mass of the markers was always ahead of that of the radioisotope. The mean difference between the methods was never greater than one region of interest, and ranged from 12 to $72 \%$ of one region of interest in the colon. The difference between these two methods could reach up to two colonic segments in certain patients at one time. Radioisotope ingestion provides accurate information about the transit through individual colonic regions because of the possibility of frequent observations and the clear delineation of the entire colon. Although these features were not obtained with radioopaque markers, they are suitable as a screening test for the presence and pattern of colonic delay.

(Gut 1993; 34: 402-408)
\end{abstract}

The use of radio-opaque markers to measure whole gut transit time has proved to be of great clinical value, ${ }^{1-3}$ since the first description of their use more than 20 years ago. The ingestion of radio-opaque markers together with a single addominal radiograph allows the distinction between those patients in whom intestinal transit is normal and those in whom it is prolonged.' More recently, this technique has been extended, in an attempt to assess the transit time through different segments of the large bowel..$^{2-5}$ While the quantification of regional colonic transit with infrequent radiographs has been validated in healthy subjects, ${ }^{5}$ the same is not true for patients with severe constipation. Yet this unvalidated method has been used to determine regional colonic delay in constipated subjects, and to choose subsequently different forms of therapy according to the results. ${ }^{6}$ While the choice of treatments based on differences in regional colonic transit may be appropriate, we felt that the methods currently used to define those differences in transit had not been adequately validated.

There is good theoretical evidence to support the view that the altered colonic motility in constipated patients will lead to an incorrect assessment of the site of colonic delay if radioopaque markers are used together with infrequent radiographs. Studies using colonic manometry together with instillation of radioisotopes have shown that high pressure peristaltic mass movements are normally responsible for most of the transport of colonic contents ${ }^{7-9}$. Studies of colonic regional transit using markers and infrequent radiographs assume that colonic transport is continuous - with normal subjects having approximately six of these propulsive events per 24 hours, this assumption is reasonable. ${ }^{10}$ In severely constipated subjects, however, these mass movements are considerably decreased in frequency, ${ }^{10}$ suggesting that infrequent radiographs may be misleading. For example, in a patient with mass movements every few days only, the result would be very different if a radiograph were taken just before or just after such an event.

Our intention was to evaluate the use of radioisotopes in quantifying regional colonic transit, using an easily prepared meal which incorporated a radioisotope of suitably long halflife. Radioisotopes are well suited to studying regional gut transit - they allow an unlimited number of observations with a low radiation dose. 112 Our second aim was to evaluate the accuracy of radio-opaque markers in determining the rate of transit through different colonic 
regions. We wished to apply this to a homogenous group of severely constipated patients.

\section{Methods}

\section{SUBJECTS}

Twelve female patients (mean age 36, range 24 55 years) with severe idiopathic constipation were studied. All had a stated spontaneous bowel frequency of less than once per week, and a colon of normal diameter shown on barium enema. All patients complained of bloating and abdominal pain.

Twelve healthy subjects with a similar age (eight women and four men, mean age 33, range 19-50 years) were studied as controls. All denied having gastrointestinal symptoms. The controls had a stated bowel frequency of 5 to 7 per week.

The study was approved by the Ethical Committee of the City and Hackney District Health Authority in 1989. Each subject gave informed written consent to participating in the study.

\section{STUDY DESIGN (FIG I)}

All patients were asked to empty their bowels as effectively as possible 2 days before the start of the study, and all succeeded with the use of laxatives or enemas. A standardised laxative was not used. The effect of the laxative was over by the time the study began in all subjects. No further laxatives, enemas, or other medications were then allowed until completion of the study. The control subjects did not take laxatives before the study.

All subjects fasted from midnight before the start of the study at 10 am the next morning. They ate a $630 \mathrm{Kcal}$ pancake containing $10 \mathrm{MBq}$ $(0.25 \mathrm{mCi})$ "'In bound to Amerlite resin microspheres (Amersham International, UK). ${ }^{13}$

The meal was specially designed to incorporate "'In into the solid phase, bound to a nonabsorbable marker so that all the isotope remained within the lumen of the bowel until excretion. The resin chosen to bind the "IIn has been shown previously to bind the isotope irreversibly. ${ }^{13}$ The resin particle size of $0.7 \mathrm{~mm}$ (range $0.5-1 \mathrm{~mm}$ ) was chosen to approximate that of triturated food. ${ }^{1+}$

While ingesting the radioisotope labelled meal, the subjects simultaneously swallowed the the different sets of radioopaque markers are shown. first set of 20 radio-opaque markers. Two further sets of radiologically distinguishable markers were ingested at 24 and 48 hours after the meal. ${ }^{5}$ Each of the three types of marker consist of a radiologically distinguishable piece of barium impregnated polyvinylchloride (rings, rods, and blocks) (Fig 1 ) and is approximately 3 to $4 \mathrm{~mm}$ in length or diameter. ${ }^{5}$ The ingested meal was used to assess gastric and small bowel transit; these data have been published elsewhere. ${ }^{15}$

Six hours after the meal subjects were allowed to eat and drink freely for the duration of the study. No subject was permitted to take any laxative, enema, or other medication till the study was completed.

\section{COLONIC SCANNING AND RADIOGRAPHS}

The subjects stood in front of a large field of view gamma camera (Siemens ZLC 7500, Germany) which images the whole abdomen. The gamma camera was fitted with a medium energy parallel collimator and peaked for $247 \mathrm{KeV}$ and $172 \mathrm{KeV}$ with a $15 \%$ window for both energies. It was linked to a Nicas 3 Nodecrest computer (UK) for data storage and analysis. Data were collected in static mode for 5 minutes for each view, allowing a high enough number of counts per frame to obtain a good image even after 7 days. To correct for tissue attenuation, each anterior view was immediately followed by a posterior view.

The first colonic scans were obtained 6 hours after the meal. On the following days scans were made three times daily at $09.00,12.00$ midday, and 16.00. Views were obtained till either all radioisotope had left the colon, or for 7 days.

A single plain abdominal radiograph was obtained at 72 hours (five patients) or 96 hours (seven patients) after ingestion of the meal and first markers, and another one at 144 or 168 hours respectively. The timing of radiographs differed slightly between the two groups because of difficulties in taking radiographs over the weekends.

\section{DATA ANALYSIS}

\section{Radioisotope data}

The determination of radioisotope counts was corrected for decay of the "'In. The geometric mean of the immediately consecutive anterior and posterior views was then determined to compensate for tissue attenuation. This was calculated according to the formula:

\section{$\sqrt{(\text { anterior count } \times \text { posterior count })}$}

To assess regional colonic radioisotope movement, eight different regions of interest (ROI) were created by visually analysing the full sequence of scans ${ }^{116^{17}}$ : region 1 - small bowel, region 2 - caecum and ascending colon, region 3 - hepatic flexure, region 4 - transverse colon, region 5 - splenic flexure, region 6 - descending colon, and region 7 - sigmoid colon and rectum, and region 8 - faeces. As the corrected total count should stay constant throughout the study, any fall in the count could be quantified as that proportion of the isotope passed in the stool, 
Figure 2: Regional colonic transit for the small bowel, six colonic regions, and faeces in one patient ( $S K)$. At each time point each individual bar represents the proportion of radioisotope in the different regions of the small bowel, colon, and faeces. Delay is

predominantly in the transverse colon. $S B=$ small bowel, $A C=$ ascending colon, $H F=$ hepatic flexutre, $T C=$ transverse colon, $S F=$ splenic flexure, $D C=$ descending colon, $R S=$ rectosigmoid colon, $F=$ faeces.

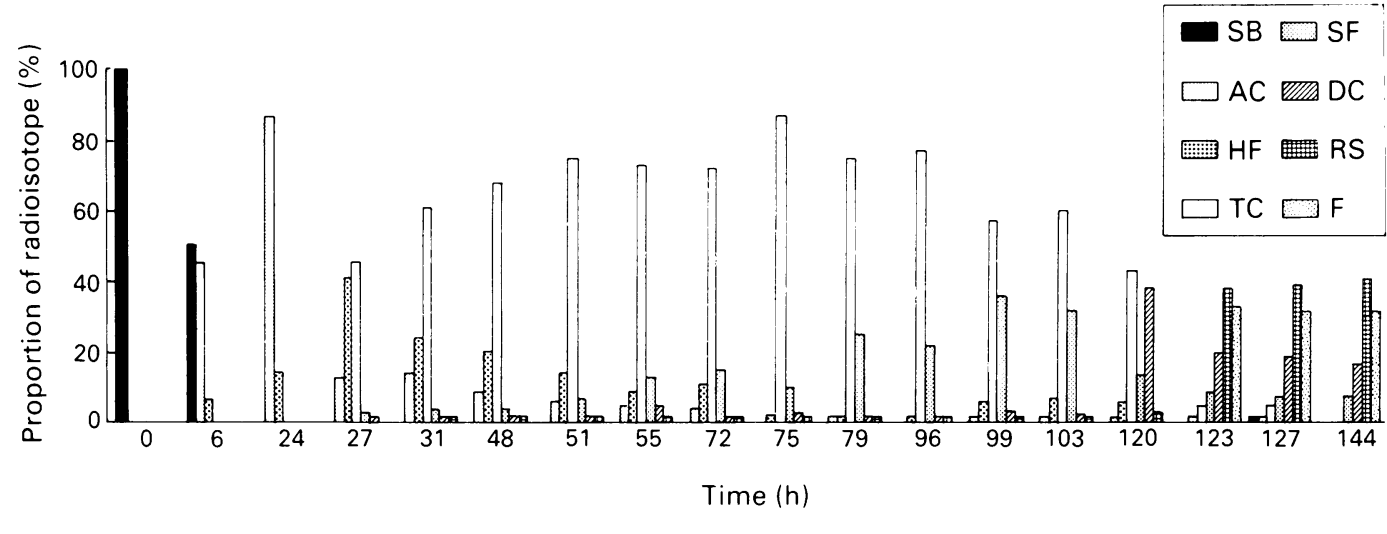

Time activity curves were created for each this was correlated with the subjects reporting a bowel action. ROI. This allows the evaluation of the proportion of radioisotope spent in each region over the scanning period. This provides an indication of the site of colonic delay. This information can be expressed as a bar graph (Fig 2) to compare the radioisotope concentration in different regions at
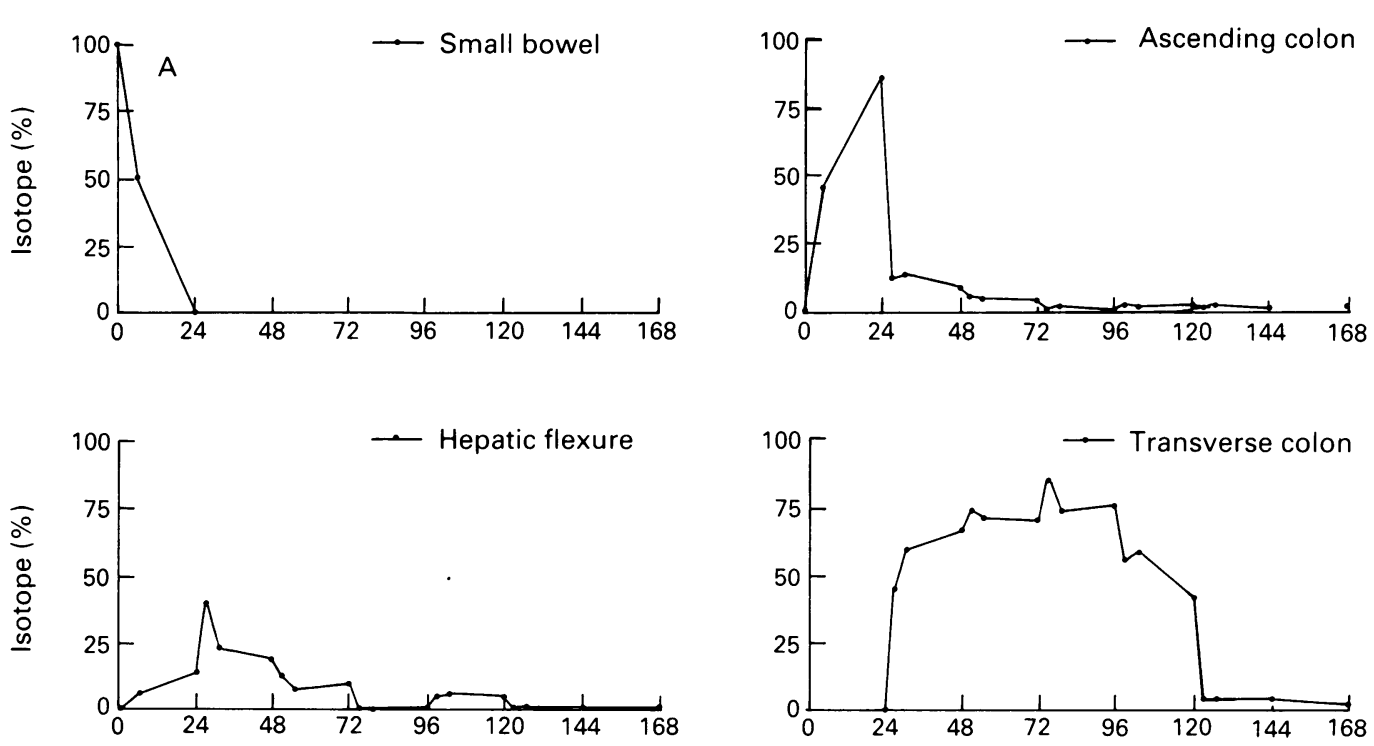

any one time, or as time activity curves for each region (Figure 3 ).

The 'centre of mass' (COM) of radioisotope of each scan was then calculated." This number reflects the distribution of radioisotope in each frame and therefore gives a guide to the effectiveness of transport. This figure represents the point in the colon (according to the predefined numbered regions) which lies ahead of $50 \%$ of

Figure 3: Time activity curve for each of the colonic regions and faeces in one patient (SK). The bulk of the isotope is seen to reside for the greatest length of time in the transverse colon. $S B=$ small bowel, $A C=$ ascending colon, $H F=$ hepatic flexure, $T C=$ transverse colon, $S F=$ splenic flexure, $D C=$ descending colon, $R S=$ rectosigmoid colon, $F=$ faeces.
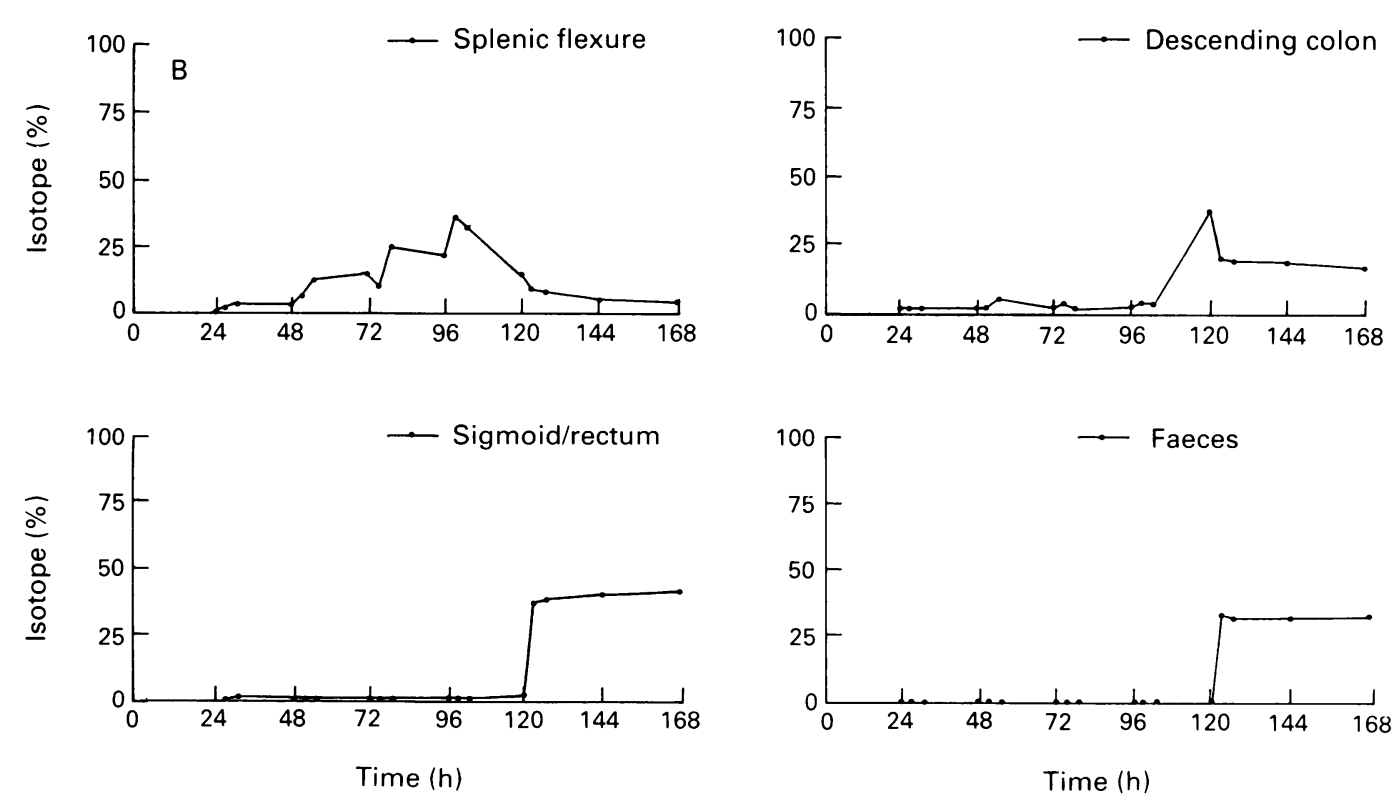


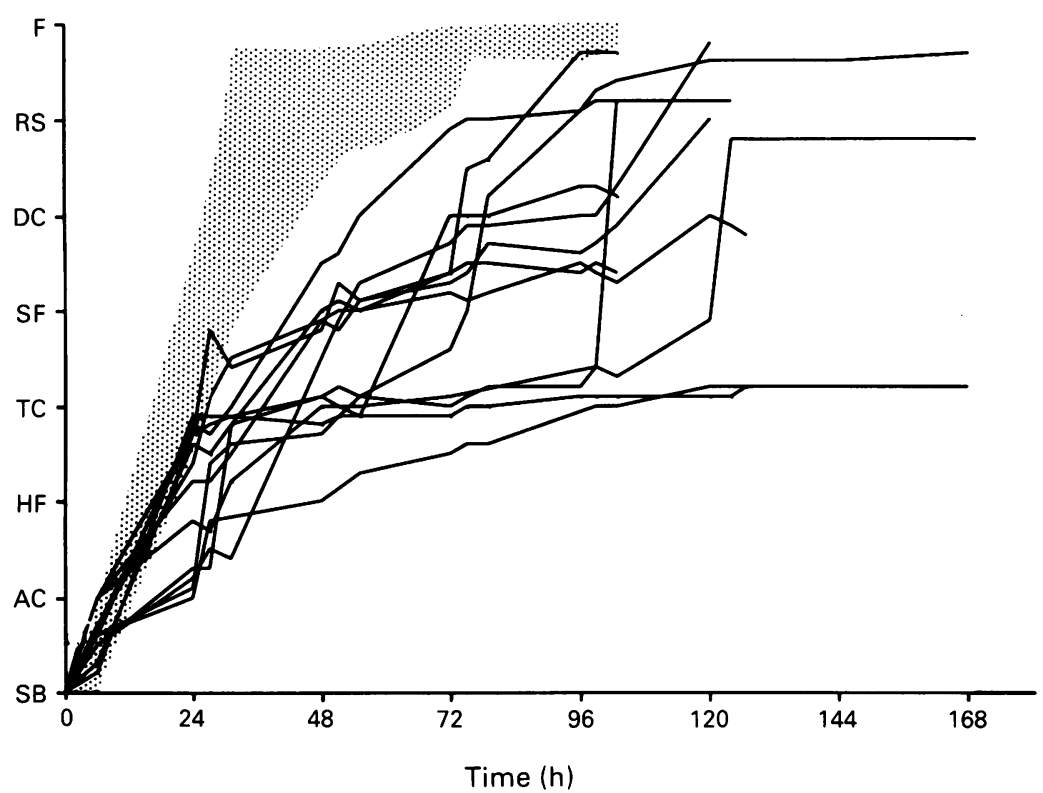

Figure 4: Centre of mass of the radioisotope in the colon at different times. The shaded area represents the data from the healthy controls, with the limits determined as mean (2SD). The progression of the centre of mass for each of the 12 patients is shown as a single line. $S B=$ small bowel, $A C=$ ascending colon, $H F=$ hepatic flexure, $T C=$ transverse colon, $T C=$ transverse colon,
$S F=$ splenic flexure, $D C=$ descending colon, $R S=$ rectosigmoid colon, $F=$ faeces.

where $n=$ frame number, $i=$ number of region of interest, (in the order originally designated) $\mathrm{ci}=$ count within the region $\mathrm{i}$.

\section{Radio-opaque marker studies}

Using the two radiographs it was possible to determine the position of each set of markers at two different times after their ingestion.

\section{STATISTICAL ANALYSIS}

The normal range derived from the healthy control subjects for the COM was determined by taking the lowest and highest values for healthy controls at each time point. This is presented graphically in Figure 4.

To determine the accuracy of the radio-opaque markers in showing regional transport, a comparison was made between the COM for the radioisotope and for the radio-opaque markers at $48,72,96,120$, and 144 hours after the beginning of the study. No comparison has been made between the markers and radioisotope for 24 and 168 hours after ingestion as the marker data are only available in too small a number of patients (five patients). For other times, the data are complete for comparison. This comparison has only been made in the constipated subjects, as in healthy controls most of the markers had been passed at the time of the first radiograph.

The comparison has been made using one way analysis of variance testing the zero hypothesis that the two methods are the same. At each time the difference between the two methods has also been expressed as the mean difference between the two methods (Table). Combining the data for three different markers it was therefore possible to determine the position of one of the sets of 20 markers at six different times after marker ingestion and the beginning of the study. For each set of markers on each of the two radiographs, their position was determined according to the same eight regions of interest, and the COM determined for each set using the same calculation.

The COM of the radio-opaque markers was determined for each 24 hour period by the same formula used for the radioisotope (see above). For the value 24 hours previous to a radiograph, the position of the markers taken 24 hours previously was assessed. Similarly the COM was determined for markers taken 48 hours previously, and so on. As three sets of markers were taken initially and two radiographs taken, six 24 hour periods of data after the start of the study could be obtained.

Comparison of the centre of mass in the colon determined from the radio-opaque markers and radioisotope (see text) in constipated patients. Values presented are for the means of the group at each time, with range of each mean value in brackets

\begin{tabular}{llll}
\hline $\begin{array}{l}\text { Time } \\
(h)\end{array}$ & $\begin{array}{l}\text { Centre of mass } \\
\text { - isotopes }\end{array}$ & $\begin{array}{l}\text { Centre of mass } \\
\text { - markers }\end{array}$ & $\begin{array}{l}\text { Mean difference } \\
\text { between 2 methods }\end{array}$ \\
\hline 48 & $4 \cdot 4(3 \cdot 0-5 \cdot 5)$ & $4 \cdot 9(2 \cdot 7-7 \cdot 4)$ & $0 \cdot 55$ \\
72 & $5 \cdot 0(3 \cdot 5-6 \cdot 9)$ & $5 \cdot 7(3 \cdot 8-7 \cdot 7)$ & $0 \cdot 54$ \\
96 & $5 \cdot 9(4 \cdot 1-7 \cdot 1)$ & $6 \cdot 2(4 \cdot 1-8 \cdot 0)$ & $0 \cdot 59$ \\
120 & $6 \cdot 1(4 \cdot 1-7 \cdot 9)$ & $6 \cdot 7(5 \cdot 0-8 \cdot 0)$ & $0 \cdot 12$ \\
144 & $6 \cdot 2(4 \cdot 2-7 \cdot 6)$ & $6 \cdot 6(4 \cdot 9-8 \cdot 0)$ & $0 \cdot 43$ \\
\hline
\end{tabular}

The difference between the two methods never reach a statistically significant difference ( $p$ always greater than $0 \cdot 05$, one way analysis of variance)

\section{RADIATION DOSE}

The calculated whole body radiation from the "In was between $3.0 \mathrm{msV}(0.06 \mathrm{rad})$ and $9.0 \mathrm{mSv}$ $(0.18 \mathrm{rad})$, depending on the time the radioisotope spend in the colon and $10 \mathrm{mSv}$ from the two abdominal radiographs. ${ }^{18}$

\section{Results}

All subjects completed the study. All normal subjects had a bowel movement with loss of radioisotope within 48 hours. All the controls had passed all the radioisotope within 103 hours of the start of the study, with an average of $2 \cdot 5$ bowel movements. None of the constipated patients cleared all the isotope within this period.

All the constipated subjects retained more than $20 \%$ of the radio-opaque markers at 96 hours, confirming overall delayed gastrointestinal transit.'

Four patients had no bowel action for the duration of the study; the other eight patients had an average of 1.8 bowel actions over the 7 day period.

In all healthy and constipated subjects all of the radioisotope was in the colon at 24 hours after ingestion.

The progression of the COM of the radioisotope was abnormally prolonged in all 12 patients (Fig 4).

The movement of the COM of the radioisotope for each constipated subject is shown in Figure 4. The normal range derived from the healthy subject is shown as a shaded area in Figure 4. Patients showed a spectrum of abnormal transit. In four patients there was slow initial transit and the COM remained at the level of the transverse colon at 96 hours. Two of these patients had movement of the COM of radioisotope to the rectosigmoid at 96 and 120 hours associated with one bowel movement during the study; the other two patients did not have further progression of 


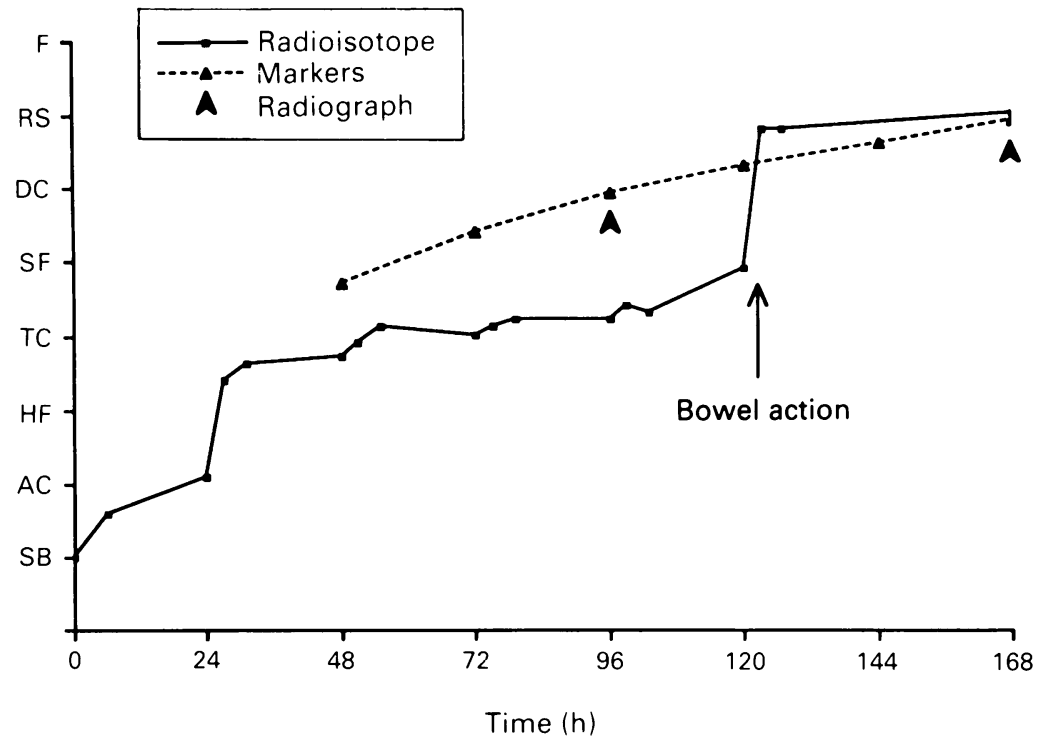

Figure 5: The progression of the centre of mass of radioisotope and radioopaque markers in one patient $(S K)$. The timing of radiographs is shown. The lack of correlation between the two methods is clearly seen - for much of the study there is two regions difference between the two methods.

$S B=$ small bowel,

$A C=$ ascending colon,

$H F=$ hepatic flexure,

$T C=$ transverse colon,

$S F=$ splenic flexure,

$D C=$ descending colon,

$R S=$ rectosigmoid colon,

$F=$ faeces.

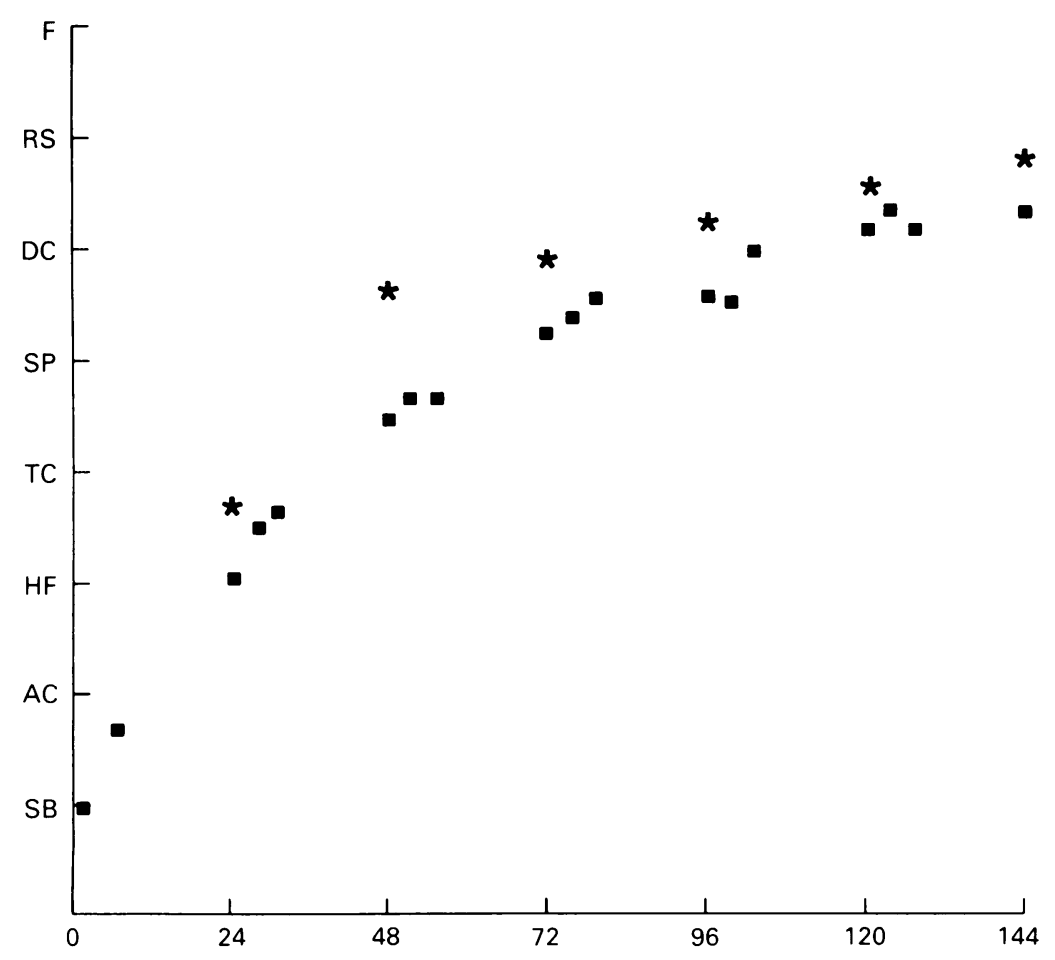

Time (h)

Figure 6: The mean values of centre of mass (COM) of radio-opaque markers and radioisotopes. The correlation between the mean COM of radio-opaque markers and mean COM

radioisotopes can be appreciated from this graph. $S B=$ small bowel, $A C=$ ascending colon,

$H F=$ hepatic flexure, $T C=$ transverse colon, $S F=$ splenic flexure, $D C=$ descending colon,

$R S=$ rectosigmoid colon, $F=$ faeces. $\mathbf{\square}=$ mean $C O M$ of radioisotope. ${ }^{\star}=$ mean $C O M$ of radioopaque markers. difference in the symptoms between patients with these different colonic scan appearances and rates of colonic transit.

It was possible to quantify further the site of radioisotope delay in individual patients (Figs 2, 3 , and 5). It was not possible to do the same with the radio-opaque markers because of the limited number of observations.

A comparison of the progression of the COM for radioisotope and radio-opaque markers in individual patients showed up to two regions of interest difference at various times during the study. An example is shown in Figure 5. The most marked differences were seen when bowel actions were infrequent but occurred between radiographs.

A comparison was made between the COM calculated from the radio-isotopes studies and from the marker studies in constipated subjects (Table). No significant difference was found between the two methods at all times. However, at every time the mean difference between the radio-opaque markers and radioisotopes was positive. In individual patients the difference at a certain time point could reach up to two regions of interest. Figure 6 shows a comparison of the mean data for markers and radioisotope in the constipated patients.

\section{Discussion}

This study has shown that the use of radioisotopes allows accurate assessment of regional colonic transit. Multiple images of the colon can easily be obtained with a low radiation dose. Scans taken three times per day allow easy determination of regional colonic radioisotope localisation. To obtain similar information using radio-opaque markers would require daily radiographs, which involves a much higher radiation dose. In addition, in contrast to marker studies, overlapping regions of the large bowel do not pose a problem when viewing sequential radioisotope scans.

"'In has a long half life of $67 \cdot 5$ hours, enabling prolonged observation. The microspheres used have been previously validated as likely to reflect accurately the movement of colonic contents. ${ }^{19}$

Unlike previous studies which involved peroral intubation of the caecum to deliver the radioisotope, ${ }^{1617}$ we have shown that it is possible to deliver the radioisotope in a physiological way, so that it becomes incorporated into, and evenly distributed within, the colonic content. The technique we have used is both simple and physiological. Stivland et $a l^{19}$ have also used a radioisotopic method to measure regional colonic transit, but incorporated the radioisotope labelled resin particles in a methacrylate coated capsule designed to dissolve at the $\mathrm{pH}$ found in the distal small bowel. ${ }^{19}$ However, in a previous study in which this method was evaluated," the coated capsule liberated the radioisotope at a variable site: in 12 subjects this was in the ascending colon or distal small bowel (exact site not specified) but in two subjects the capsule did not dissolve until it was in the transverse colon. We believe that the method used in this study is both simpler and more reliable in allowing imaging of the whole colon. In every subject all 
of the radioisotope was in the colon at 24 hours, and images of all colonic regions were obtained. Delivery of radioisotope as a bolus does not seem to offer any advantage; the period of interest is between 24 and 168 hours.

Krevsky $e a^{16}$ studied regional colonic transit in constipated subjects using radioisotope instilled into the caecum by a peroral tube. This allowed a clear distinction between those patients which apparently slow transit throughout the colon and those with delay in the distal large bowel only. ${ }^{16}$ However the effect of the tube on intestinal motility is unknown. Strivland $e t a l^{19}$ studied eight patients with severe constipation and five healthy controls, but one of the patients had a previous diagnosis of chronic idiopathic intestinal pseudo-obstruction. They used a coated capsule to release the radiosotope in the ileocaecal region. The site of delayed colonic transit varied in individual patients, a finding similar to our own.

There are several ways that radioisotope transit data from the colon can be analysed. The COM gives a simple overall numerical measure of the rate of transport but does not indicate whether the radioisotope is fragmented in different regions or is moving as a single bolus. Nor does it provide a measure of transit through each region. However, this latter type of precise quantitative information about the transit through a particular colonic region can be obtained from time activity curves as shown in Figure 3.

Without daily radiographs the marker data at 48 and 72 hours (if a radiograph is taken at 96 hours) or 24 and 48 hours (if a radiograph is taken at 72 hours) is necessarily extrapolated from these later radiographs. This is unlikely to be as accurate as real observations which can be obtained using a radioisotopic method. The radio-opaque markers do not provide accurate data on transit through each colonic region. This is important for research studies, but the value of these observations in clinical practice remain to be proven.

In practice, the radioisotope and radioopaque marker methods of regional transit gave very similar results when determining the COM. At most, there was the equivalent of one ROI difference in the mean data for the location of the COM. As a simple test, therefore, the use of radio-opaque markers to determine the pattern of colonic transit seems justified.

Because of the frequency of observations in real time with the radioisotope and its physiological incorporation into the gut content, we would regard it as reliable and therefore the gold standard in measurements of colonic transit.

A further advantage of using a radiolabelled meal is the ability to study gastric emptying and small bowel transit as part of the same study. In view of the panenteric motility disturbance in many of these patients. ${ }^{152122}$ we believe that this is important.

Some differences in transport between the markers and radioisotope may be the result of a true difference in the rate of transport of the two types of particle. Hinton et al' compared the rate of passage of radio-opaque markers with that of ${ }^{51} \mathrm{Cr}$-labelled sodium chromate. They found that the transit time for the first appearance of markers and radioisotope in the stool were very similar, but that the transit time for the bulk of radio-opaque markers was shorter than for radioisotope. Stivland et $a l^{20}$ also compared radioisotope with radio-opaque markers and found that the latter were consistently faster in their transit though the right colon than the radioisotope. While this may be a true reflection of a difference between the two methods, it may also reflect a difference in calculations - the marker data was derived from infrequent radiographs.

An additional difference between the two methods relates to anatomical localisation. In radioisotope studies the concentration of radioisotope in different colonic regions can be easily determined by examining sequential scans. In the plain radiograph used for marker studies there is often overlap of bowel segments, making precise localisation of all markers difficult or inaccurate.

This study has highlighted the disturbances of colonic transit which occur in patients with severe idiopathic constipation. Many of these patients also show disturbances of pelvic floor coordination $^{23}$ but it is not well established whether these contribute pathophysiologically to the abnormality in colonic motility. ${ }^{24}$

Radio-opaque markers and two radiographs provide a reasonable screening test to determine whether whole gut transit is prolonged and to assess the pattern of colonic regional transit, despite our initial reservations. The difference in determining regional delay between radioisotope and markers represents approximately one colonic segment. For routine evaluation this difference may be unimportant, but if the results are used to determine segmental resection, ${ }^{25}$ for example, then it may be necessary to use the more precise radioisotope method of defining transit through each region with time-activity curves. The accuracy of radioisotope methods for measuring regional transit may be necessary for research purposes and to determine the effectiveness of therapies based on localised colonic or rectal abnormalities.

We are grateful for the use of the facilities of the Imperial Cancer Research Fund. We thank David Ellison for his technical assistance in preparing the meal. We thank Jan Roelofs for his assistance in the statistical analysis of the results.

1 Hinton JM, Lennard-Jones JE, Young AC. A new method for studying gut transit times using radiopaque markers. $G u$ $1969 ; 10: 842-7$

2 Martelli H, Devroede G, Arhan P, Duguay C, Dornic C, Faverdin $C$. Some parameters of large bowel motility in normal man. Gastroenterology 1978; 75:612-8.

3 Arhan P, Devroede G, Jehannu B, et al. Segmental colonic transit time. Dis Colon Rectum 1981; 24: 625-9.

4 Chaussade S, Khyari A, Roche H, Garret M, Gaudric M, Couterier D, et al. Determination of total and segmental colonic transit time in constipated patients. Results in 91 colonic transit time in constipated patients. Results in 91
patients wth a new simplified method. Dig Dis Sci 1989; 34 : patients wth
$1168-72$.

5 Metcalf AM, Phillips SF, Zinsmeister AR, MacCarty RL Beart RW, Wolff BG. Simplified assessment of segmental Beart RW, Wolff BG. Simplified assessment of

6 Wexner SD, Daniel N, Jagelman DG. Colectomy for constipation: physiologic investigation is the key to success. Dis Colon Rectum 1991; 34: 851-6.

7 Reddy SN, Di Lorenzo C, Yanni G, Bazzochi G, VillaneuveMeyer J, Mena I, et al. A unified approach to the study of colonic scintigraphy and intraluminal pressure. Gatroenterologv 1990; 98: A383

8 Spiller RC, Brown ML, Phillips SF. Decreased fluid tolerance, accelerated transit and abnormal motility of the human colon induced by oleic acid. Gastroenterologv 1986; 91: 100-7. 
9 Cook IJ, Furakawa Y, Panagopoulos V, Collins PJ, Simula M, Dent J. Correlation between intraluminal pressure and movement of contents in healthy human colon: a combined manometric and isotope transit study. Gastroenterology 1990; 98: A338.

10 Bassotti G, Gaburri M, Imbimbo PB, Rossi L, Farroni F, Pelli MA, et al. Colonic mass movements in idiopathic chronic constipation. Gut 1988; 29:1173-9.

11 Kamm MA. Colonic scintygraphy. In: Read NW, ed. Gastrointestinal motility: which test? Petersfield: Wrightson intestinal motility: which test?

12 Krevsky B, Malmud LS, D'ercole F, Maurer AH, Fisher RS. Colonic transit scintigraphy. A physiological approach to quantative measurements of colonic transit in humans Gastroenterology 1986; 91: 1102-12.

13 Mather SJ, Ellison D, Nightingale JMD, Kamm MA, Britton KE. Design of a two-phase radiolabelled meal for gastric emptying studies. Nucl Med Commun 1991; 12: 409-12. 14 Meyer JH. The physiology of gastric motility and gastric
emptying. In: Yamada T, ed. Textbook of gastroenterology. Philadelphia: JB Lippincott, 137-52.

15 van der Sijp JRM, Kamm MA, Nightingale JMD, Walker E Granowska M, Britton $\mathrm{K}$, et al. Evidence for disturbed gastric and panenteric transit in patients with severe idiogastric and panenteric transit in patients with severe
pathic constipation. Gastroenterology 1991; 100: A503.

16 Krevsky B, Maurer AH, Fisher RS. Patterns of colonic transit in chronic idiopathic constipation. Am $\mathcal{F}$ Gastroenterol 1989; in chronic $127-32$.

17 Kamm MA, Lennard-Jones JE, Thompson DG, Sobnack $R$, Garvie NW, Granowska M. Dynamic scanning defines a colonic defect in severe idiopathic constipation. Gut 1988; 29: $1085-92$.
18 Siegel JA, Wu RK, Knight LC, Zelac RE, Stern HS, Malmud LS. Radiation dose estimates for oral agents used in upper gastrointestinal disease. 7 Nucl Med 1983; 24: 835-7.

19 Stivland TA, Camilleri M, Vassallo M, Proano M, Rath DM, Brown ML, et al. Scintigraphic measurement of regional colonic transit in idiopathic constipation. Gastroenterology 1991; 10: 107-15.

20 Proano M, Camilleri M, Phillips SF, Brown ML, Thomforde GM. Transit of solids through the human colon: regional
quantification in the unprepared bowel. Am $\mathcal{F}$ Physiol 1990; 258: G856-62.

21 Reynolds JC, Ouyang A, Lee CA, Baker C, Sunshine AG, Cohen S. Chronic severe constipation: prospective motility studies in 25 consecutive patients. Gastroenterology 1987; 92: 414-20.

22 Watier A, Devroede G, Durenceau A, Abdel-Rahman M, Duguay $\mathrm{C}$, Forand $\mathrm{MD}$, et al. Constipation with colonic inertia, A manifestation of systemic disease? Dig Dis $\mathrm{Sc}$ 1983; 28: 1025-33.

23 Preston DM, Lennard-Jones JE. Anismus in chronic constipation. Dig Dis Sci 1985; 30: 413-8.

24 Kamm MA. Pathophysiology of constipation. In: Phillips SF, Pemberton JH, Shorter RG, eds. The large intestine. Physiology, pathophysiology and disease. New York: Raven Press, 1991, 709-26.

25 Kamm MA, van der Sijp JRM, Hawley PR, Phillips RKS, Lennard-Jones JE. Left hemicolectomy wth rectal excision for severe idiopathic constipation. Int $\mathcal{F}$ Colorectal Dis 1991; 6: 49-51 